\title{
NMDA Receptor Subunit NR2A Is Required for Rapidly Acquired Spatial Working Memory But Not Incremental Spatial Reference Memory
}

\author{
David M. Bannerman, ${ }^{1}$ Burkhard Niewoehner, ${ }^{1}$ Louisa Lyon, ${ }^{1}$ Carola Romberg, ${ }^{1}$ Wolfram B. Schmitt, ${ }^{1}$ Amy Taylor, ${ }^{1}$ \\ David J. Sanderson, ${ }^{1}$ James Cottam, ${ }^{1}$ Rolf Sprengel, ${ }^{2}$ Peter H. Seeburg, ${ }^{2}$ Georg Köhr, ${ }^{2}$ and John N. P. Rawlins ${ }^{1}$ \\ ${ }^{1}$ Department of Experimental Psychology, University of Oxford, Oxford OX1 3UD, United Kingdom, and ${ }^{2}$ Max Planck Institute of Medical Research, \\ Department of Molecular Neurobiology, D-69120 Heidelberg, Germany
}

\begin{abstract}
NMDA receptors (NMDARs) containing NR2A $(\varepsilon 1)$ subunits are key contributors to hippocampal long-term potentiation (LTP) induction in adult animals and have therefore been widely implicated in hippocampus-dependent spatial learning. Here we show that mice lacking the NR2A subunit or its C-terminal intracellular domain exhibit impaired spatial working memory (SWM) but normal spatial reference memory (SRM). Both NR2A mutants acquired the SRM version of the water maze task, and the SRM component of the radial maze, as well as controls. They were, however, impaired on a non-matching-to-place T-maze task, and on the SWM component of the radial maze. In addition, NR2A knock-out mice displayed a diminished spatial novelty preference in a spontaneous exploration Y-maze task, and were impaired on a T-maze task in which distinctive inserts present on the floor of the maze determined which goal arm contained the reward, but only if there was a discontiguity between the conditional cue and the place at which the reward was delivered. This dissociation of spatial memory into distinctive components is strikingly similar to results obtained with mice lacking glutamate receptor-A (GluR-A)-containing AMPA receptors, which support long-term potentiation expression. These results identify a specific role for a NMDAR-dependent signaling pathway that leads to the activation of a GluR-A-dependent expression mechanism in a rapidly acquired, flexible form of spatial memory. This mechanism depends on the C-terminal intracellular domain of the NR2A subunit. In contrast, the ability to associate a particular spatial location with the water maze escape platform or food reward is NR2A independent, as well as GluR-A independent.
\end{abstract}

Key words: hippocampus; long-term potentiation; synaptic plasticity; water maze; radial maze; T-maze

\section{Introduction}

There is great interest in the contribution made by different NR2 NMDA receptor (NMDAR) subunits to different forms of synaptic plasticity (Liu et al., 2004; Berberich et al., 2005; Morishita et al., 2007). Ultimately the functional significance of these findings can only be ascertained by investigating the behavioral effects of selectively manipulating these different NMDAR subunits. NMDAR-dependent synaptic plasticity in the hippocampus is widely hypothesized to be the neural mechanism underlying spatial memory (Morris et al., 1986; Martin et al., 2000). Spatial memory can be differentiated into distinct components with different molecular substrates. Whereas mice with

Received May 14, 2007; revised Nov. 9, 2007; accepted Dec. 4, 2007.

This work was supported by Wellcome Trust Grant 074385 to D.M.B., by grants from the Deutsche Forschungsgemeinschaft to R.S. (SP602/1 and SFB633/4), and by the European Union (EU) Framework 6 program-EU Synapse to P.H.S. (0190552PHS). B.N. was supported by a Prize Studentship associated with Wellcome Trust Grant 073087 to Jonathan Flint and J.N.P.R. Behavioral experiments were conducted under the auspices of United Kingdom Home Office Project and personal licenses held by the authors. We thank Prof. M. Mishina for providing the NR2A knock-out mice.

Correspondence should be addressed to David M. Bannerman, Department of Experimental Psychology, University of 0xford, South Parks Road, 0xford 0X1 3UD, UK. E-mail: david.bannerman@psy.ox.ac.uk.

D0I:10.1523/JNEUROSCI.3639-07.2008

Copyright $\odot 2008$ Society for Neuroscience $\quad$ 0270-6474/08/283623-08\$15.00/0 hippocampal lesions are impaired on both spatial working memory (SWM) and spatial reference memory (SRM) tests, genetically modified mice lacking the glutamate receptor-A (GluR-A; also known as GluR1) AMPA receptor subunit $\left(G l u R-A^{-1-}\right.$ mice), which is required for long-term potentiation (LTP) expression in adult mice (Zamanillo et al., 1999; Hoffman et al., 2002; Malinow and Malenka, 2002; Jensen et al., 2003), display a strikingly different phenotype. They exhibit normal hippocampus-dependent SRM performance on a number of tasks, including the water maze, while being profoundly impaired on hippocampus-dependent SWM tasks (Reisel et al., 2002; Schmitt et al., 2003, 2005). These results suggest that there are two spatial information-processing mechanisms, both dependent on the hippocampus for expression, but supported by distinct molecular pathways.

NMDARs have been implicated in both SWM (Tonkiss and Rawlins, 1991; Steele and Morris, 1999; Lee and Kesner, 2002; Nakazawa et al., 2003) and SRM (Morris et al., 1986; Sakimura et al., 1995; Tsien et al., 1996) [but see also Bannerman et al. (1995) and Saucier and Cain (1995)]. However, the contribution that different NR2 subunits make to these distinct aspects of spatial information processing remains to be established. The NR2A subunit is a key contributor to hippocampal LTP induction in 
adult animals. Mice lacking the NR2A subunit (NR2 $A^{-/-}$mice) exhibit reduced LTP and a mild impairment on the fixedlocation, hidden-platform SRM water maze task has been reported (Sakimura et al., 1995). The contribution of NR2A to SWM, however, has not been examined. We therefore assessed the contribution of NR2A-dependent synaptic plasticity to different aspects of spatial information processing, comparing the performance of $N R 2 A^{-/-}$and wild-type mice on several hippocampus-dependent tests of SRM and SWM.

The mechanisms through which NMDAR activation alters synaptic strength and thus supports spatial memory are not yet fully delineated, but the C-terminal domain of the NR2A subunit is thought to play a pivotal role in directing these signaling pathways (Kohr et al., 2003). We therefore also included a group of $N R 2 A^{\Delta C / \Delta C}$ mice, which express NR2A subunits lacking the intracellular C-terminal domain (Sprengel et al., 1998). NR2A $\Delta$ Ccontaining NMDARs fail to activate NR2A-specific intracellular signaling pathways, despite contributing to channel formation, synaptic localization, and $\mathrm{Ca}^{2+}$ signaling, resulting in impaired CA3-CA1 LTP (Steigerwald et al., 2000; Kohr et al., 2003).

We now show that mice lacking either the NR2A subunit or its C-terminal intracellular domain exhibit impaired SWM. In contrast, and contrary to expectation, SRM, as typified by the fixedlocation, hidden-platform water maze task, is NR2A independent.

\section{Materials and Methods}

Subjects

The $N R 2 A^{-1-}$ mice were initially produced by homologous recombination in embryonic stem (ES) cells from a C57BL/6 × CBA F1 hybrid [ES cell line TT2 (Yagi et al., 1993)], using a targeting vector with genomic DNA from a C57BL/6 mouse (Sakimura et al., 1995). They were then subsequently back-crossed repeatedly with $\mathrm{C} 57 \mathrm{BL} / 6$ mice to yield $N R 2 A^{-1-}$ and wild-type mice on a more pure C57BL/6 genetic background (Kiyama et al., 1998). The $N R 2 A^{-1-}$ mice were initially provided by M. Mishina. The NR2A $A^{\Delta C / \Delta C}$ mice were produced by homologous recombination in R1 ES cells derived from a $129 / \mathrm{SV} \times 129 \mathrm{~Sv} / \mathrm{J} \mathrm{F} 1$ hybrid (Nagy et al., 1993), using a targeting vector with genomic DNA from a SV129/SV mouse, and then subsequently back-crossed repeatedly with C57BL/6 mice (Sprengel et al., 1998). All mice were bred at the Max Planck Institute of Medical Research (Heidelberg, Germany), before being transported to Oxford (UK) for behavioral testing. Electrophysiological characterization of the $N R 2 A^{-1-}$ and $N R 2 A^{\Delta C / \Delta C}$ mice were conducted initially by Sakimura et al. (1995) and Sprengel et al. (1998), respectively, but have also been further investigated more recently (Kiyama et al., 1998; Kohr et al., 2003; Berberich et al., 2007).

Experiments 1-3 were conducted with a single cohort of experimentally naive, age-matched, male mutant and wild-type mice, 2-3 months of age at the start of behavioral testing, under the auspices of UK Home Office Project and Personal licenses held by the authors. The wild-type control group consisted of littermates of both NR2A mutants. Each of these spatial learning experiments was conducted in a different laboratory. The testing rooms were all distinct from each other and contained a variety of extramaze spatial cues, including racks of equipment, shelving and cupboards, benching, wall posters, empty racks of animal caging, and a medical screen (water maze room). Experiment 4 used a further cohort of experimentally naive, age-matched, male and female mutant and wild-type mice. Experiment 5 used further separate cohorts of experimentally naive, age-matched, male mutant and wild-type mice.

Experiment 1: spatial reference memory in the hidden-platform water maze task

Experimentally naive wild-type $(n=20), N R 2 A^{-1-}(n=15)$, and $N R 2 A^{\Delta C / \Delta C}$ mice $(n=7)$ were first compared on the standard, hippocampus-dependent, SRM version of the Morris water maze task (Morris et al., 1982). Mice were trained in the same open field water maze that we have used previously (diameter, $2.0 \mathrm{~m}$ ) (Deacon et al., 2002; Reisel et al., 2002). These previous studies, conducted in the same testing room, using identical spatial cues, and using the same testing protocol, have revealed a striking and enduring deficit in mice with cytotoxic hippocampal lesions (Deacon et al., 2002) (see also Reisel et al., 2002). To escape from the water, the mice had to find a hidden escape platform (diameter, $21 \mathrm{~cm}$ ) submerged $\sim 1 \mathrm{~cm}$ below the water surface, which remained in a fixed location throughout testing. The platform was located at the center of one of the four quadrants of the pool (arbitrarily designated NE, NW, SE, and SW). The number of mice trained to each platform position was counterbalanced with respect to group. Animals had no swim pretraining before the start of spatial testing in the water maze. They received 4 trials/d for $9 \mathrm{~d}$, with an intertrial interval (ITI) of $\sim 15 \mathrm{~s}$. Mice were placed into the pool facing the side wall at one of eight start locations (nominally N, S, E, W, NE, NW, SE, and SW; chosen randomly across trials), and allowed to swim until they found the platform, or for a maximum of $90 \mathrm{~s}$. Any mouse that failed to find the platform within the allotted time was lifted out of the water by the experimenter and placed onto the platform. The animal then remained on the platform for $30 \mathrm{~s}$ before commencing the $15 \mathrm{~s}$ ITI before the next trial. On the seventh $(24 \mathrm{~h}$ after spatial training trial 24$)$ and tenth $(24 \mathrm{~h}$ after spatial training trial 36 ) days of testing, a probe trial was conducted to determine the extent to which the mice had learned about the spatial location of the platform. The platform was removed from the pool and the mice allowed to swim ad libitum for $60 \mathrm{~s}$.

\section{Experiment 2: spatial working memory on the elevated T-maze}

Hippocampus-dependent SWM was assessed on an elevated T-maze (Deacon et al., 2002; Reisel et al., 2002). Previous studies in the laboratory have shown that mice with cytotoxic hippocampal lesions exhibit chance levels of performance on this rewarded alternation task (50\% correct) (Deacon et al., 2002). The same wild-type $(n=19), N R 2 A^{-1-}(n=14)$, and $N R 2 A^{\Delta C / \Delta C}(n=7)$ mice were maintained on a restricted feeding schedule at $85 \%$ of their free-feeding weight and habituated to the maze, and to drinking sweetened, condensed milk (diluted 50/50 with water), over several days before spatial non-matching-to-place testing.

For spatial non-matching-to-place testing, each trial consisted of a sample run and a choice run. On the sample run, the mice were forced either left or right by the presence of a wooden block, according to a pseudorandom sequence (with equal numbers of left and right turns per session, and with no more than two consecutive turns in the same direction). A $0.1 \mathrm{ml}$ reward was available in the food well at the end of the arm. The block was then removed, and the mouse was placed, facing the experimenter, at the end of the start arm and allowed a free choice of either arm. The delay interval between the sample run and the choice run was $\sim 10-15 \mathrm{~s}$. The animal was rewarded for choosing the previously unvisited arm (i.e., for alternating). For this test and all subsequent experiments, entry into an arm was defined when a mouse placed all four paws into that arm. Mice were run one trial at a time with an ITI of $\sim 10$ min. Mice received 50 trials in total over $10 \mathrm{~d}$ of testing ( 5 trials/d).

\section{Experiment 3: assessment of spatial memory on the radial maze} Spatial reference memory acquisition. Hippocampus-dependent spatial memory was further assessed using a six-arm radial maze task (Schmitt et al., 2003). Wild-type $(n=13), N R 2 A^{-/-}(n=13)$, and NR2A ${ }^{\Delta C / \Delta C}$ mice $(n=7)$ were first trained to discriminate between baited and nonbaited arms. Again, previous studies conducted in the same testing room as used here, using identical spatial cues and the same testing protocol, have revealed a striking and enduring deficit in spatial reference memory acquisition on this task in mice with cytotoxic hippocampal lesions (Schmitt et al., 2003, their Fig. 4). The same three of six arms were always baited and were allocated such that two of these arms were adjacent, and the third was between two nonrewarded arms (e.g., arms 1, 2, and 4). Different combinations of arms were used as far as possible, although the arm allocations were counterbalanced across groups. Mice were placed on the central platform and allowed to explore the maze until they had collected the three milk rewards. They were then removed from the maze and returned to their home cages between trials. During this acquisition phase, Perspex doors prevented mice from reentering an arm that they had already visited on that trial (Schmitt et al., 2003). All the doors were closed each time the mouse returned to the central platform, and con- 
fined the mouse there for $5 \mathrm{~s}$ until the next choice. Once an arm had been visited, its door remained closed for subsequent choices. Thus, all six doors were open for the first choice, five for the second choice, four for the third choice, and so on. Using this testing procedure, it was not possible for the mice to make working memory errors. Reference memory errors were defined as entries into arms that were never baited (maximum of three errors per trial). Entry into an arm was defined when a mouse placed all four paws into that arm. The maze was rotated periodically to prevent the mice from using intramaze cues to solve the task. Mice received 60 trials in total (4 trials/d where possible). Data were arranged in 15 blocks of four trials for analysis. By this stage, all animals had acquired the reference memory component of the task, making very few, if any, errors.

Simultaneous assessment of spatial working and reference memory. The working memory component of the task was then introduced. Mice received a further 24 trials (with an interchoice interval of $5 \mathrm{~s}$ ) in which the same three of six arms were baited, but now they were no longer prevented from reentering a previously chosen arm. The doors were solely used to retain the animals on the central platform between choices. Working memory errors were scored when a mouse entered an arm that had already been visited on that trial. Reference memory errors were scored as before.

\section{Experiment 4: spontaneous spatial novelty preference test}

Spontaneous spatial novelty preference was assessed in a separate cohort of experimentally naive wild-type $(n=29)$ and NR2A ${ }^{-1-}(n=19)$ mice. This test assesses rapidly acquired, short-term spatial memory and relies on the fact that normal mice prefer novel over familiar spatial environments. These mice had no previous experience of any maze testing, or of the laboratory in which the experiment was conducted. The spontaneous spatial novelty preference test was conducted using a Y-maze constructed from transparent Perspex. Each arm was $30 \mathrm{~cm}$ long, $8 \mathrm{~cm}$ wide, with 20-cm-high walls (Sanderson et al., 2007). Mice were assigned two arms ("start arm" and "other arm"), to which they were exposed during the first phase of the test (the exposure phase). During this exposure phase, the entrance to the third arm of the maze (the "novel arm" during the subsequent test phase) was blocked off with a sheet of opaque Perspex. Allocation of arms (start, other, and novel) to specific spatial locations was counterbalanced within each experimental group. For the exposure phase, mice were placed at the end of the start arm and were allowed to explore the start arm and the other arm for 5 min (beginning from the time the mouse first left the start arm). Entry into an arm was defined when a mouse placed all four paws into an arm, and similarly a mouse was considered to have left an arm if all four paws were placed outside that arm. The mouse was then removed from the maze and returned to its home cage for $1 \mathrm{~min}$. The mouse was then returned to the maze for the test phase, during which it now had ad libitum access to all three arms of the maze. The mouse was again placed at the end of the start arm and allowed to explore for $2 \mathrm{~min}$ (again beginning from the time the mouse first left the start arm). The amount of time the mouse spent in each of the arms of the maze and the number of entries into each arm were recorded during both the exposure phase and during the test phase. For the test phase, a discrimination ratio [novel arm/(novel + other arm)] was calculated for both arm entries and time spent in arms. Our previous study has shown that normal control mice show a preference for the novel (previously unvisited) arm during the test phase, and that this preference relies on the extramaze cues. Intramaze cues are not sufficient to support the novel arm preference. Furthermore, mice with cytotoxic hippocampal lesions show no preference whatsoever for the novel arm (Sanderson et al., 2007, their Fig. 6).

\section{Experiment 5: conditional learning on the T-maze}

Conditional learning was assessed on the same elevated T-maze as used for spatial non-matching-to-place testing (see also Schmitt et al., 2004). A floor insert of either white Perspex or wire mesh $(5 \times 5 \mathrm{~mm}$ mesh, affixed to a gray painted, wooden backing) could be placed into the maze to act as a conditional cue or occasion setter, indicating which goal arm was rewarded. Two separate, new cohorts of experimentally naive mice were used for these experiments.
Contiguous task. Experimentally naive wild-type $(n=10)$ and $N R 2 A^{-i-}(n=10)$ mice were trained on a conditional learning task with floor inserts, extending throughout the entire maze, including the start arm and both of the goal arms. Acquisition of this task does not require the hippocampus (Schmitt et al., 2004). Mice with cytotoxic hippocampal lesions are capable of acquiring this particular version of the task. For half of the wild-type and $N R 2 A^{-1-}$ animals, the presence of the white Perspex insert indicated that the $0.1 \mathrm{ml}$ milk reward was available in the left-hand goal arm. In contrast, the reward was in the right-hand goal arm if the maze contained the wire-mesh floor insert. For the remaining wild-type and $N R 2 A^{-1-}$ mice, the opposite pair of floor insert/reward contingencies applied (e.g., Perspex/right, wire/left). The relationship between the floor insert and the rewarded goal arm was constant for each animal throughout the experiment. Mice received 14 test sessions comprising 10 trials per session with an ITI of 5-10 min. Each session consisted of five trials with each of the two floor inserts, and no more than three consecutive trials with the same floor insert, according to a pseudorandom sequence. During sessions 11 and 12, the milk reward was delivered into the food well only after the mouse had made a choice. This was to ensure that the mice were unable to solve the task by smelling the milk reward.

Discontiguous task. Separate groups of experimentally naive wild-type $(n=10)$ and NR2A $A^{-/-}$mice $(n=10)$ were tested as in the "contiguous" experiment, but with the only exception being that the floor inserts now covered just the start arm $(57 \times 10 \mathrm{~cm}$; extending right across to the wall opposite the start arm at the junction of the maze). Acquisition of this task does require the hippocampus (Schmitt et al., 2004). Mice with cytotoxic hippocampal lesions are completely unable to acquire this version of the task, although task acquisition is not impaired by medial prefrontal cortical lesions (Delatour and Gisquet-Verrier, 1999). Mice received 24 test sessions of 10 trials. During sessions 21 and 22, the milk reward was delivered into the food well only after the mouse had made a choice.

\section{Results}

Experiment 1: spatial reference memory in the hiddenplatform water maze task

In contrast to Sakimura et al. (1995), we found no impairment in the $N R 2 A^{-/-}$mice during acquisition of the standard, hippocampus-dependent, SRM version of the Morris water maze task (Fig. 1). Similarly, the $N R 2 A^{\Delta C / \Delta C}$ mice were also indistinguishable from controls. Analysis of path lengths taken to reach the platform during training revealed that all three groups of mice acquired the task at the same rate (main effect of block, $F_{(8,312)}=$ 93.46; $p<0.0001$; main effect of genotype, $F_{(2,39)}=1.40 ; p>$ 0.20 ; genotype-by-block interaction, $F_{(16,312)}=2.28 ; p<0.01$ ) (Fig. $1 A$ ). The significant interaction was attributable to group differences on blocks 1 and 2 of testing, but these differences did not reflect consistently better performance in any one group relative to any of the other groups. There was also a main effect of trial within a block $\left(F_{(3,117)}=5.74 ; p<0.005\right)$, but, importantly, no genotype-by-trial or genotype-by-block-by-trial interaction (both $F<1$ ), demonstrating that performance across the four training trials within a day also did not differ between groups.

Performance was also assessed during two probe tests conducted $24 \mathrm{~h}$ after trial 24 (transfer test 1) and after trial 36 (transfer test 2), during which the platform was removed from the pool and the mice were allowed to swim ad libitum for $60 \mathrm{~s}$. Again, the data revealed that all three groups of mice had learned about the location of the platform to the same extent (Fig. $1 B, C$ ). Analysis of the distribution of time spent in the four quadrants of the pool revealed a significant effect of quadrant for both probe tests (test $1, F_{(2,117)}=17.18 ; p<0.01$; test $\left.2, F_{(2,117)}=45.95 ; p<0.01\right)$, but no genotype-by-quadrant interactions (both $F<1$ ). Further analysis of time spent in the training quadrant only also revealed no group differences for either of the probe tests (both $F<1$ ). 
A

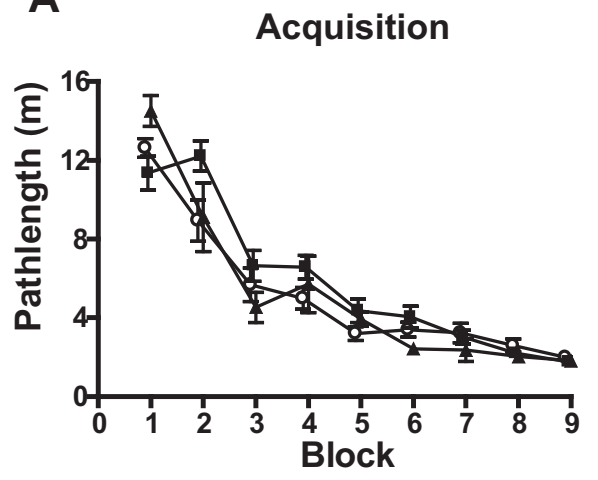

B

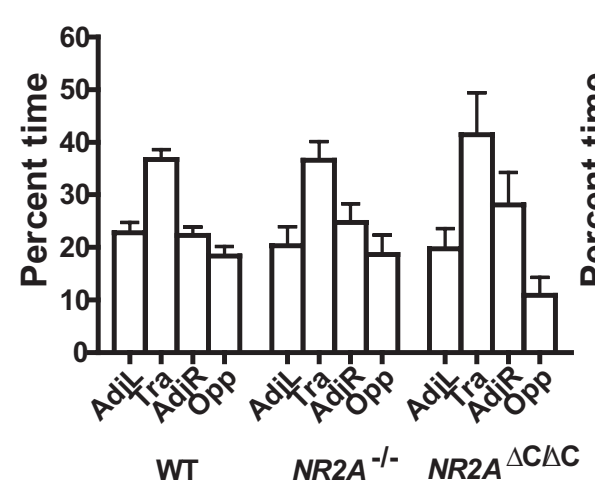

C

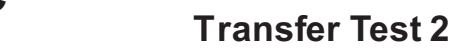

Figure 1. Normal NR2A expression is not required for spatial reference memory in the Morris water maze. $A$, Mean path length \pm SEM during acquisition of the reference memory task for wild-type (O), NR2A $A^{-1-}(\square)$, and $N R 2 A^{\Delta C / \Delta C}$ mice ( $\left.\mathbf{A}\right)$. B, Transfer test 1 after 24 trials; mean percentage time \pm SEM in the adjacent left (AdjL), training (Tra), adjacent right (AdjR), and opposite (Opp) quadrants. C, Transfer test 2 after 36 trials. WT, Wild-type.

Similarly, inspection of annulus crossings data revealed equivalent learning in all three groups of mice at both transfer tests (data not shown). Mice showed a significantly greater number of platform crossings in the "training" quadrant relative to crossings in the other three quadrants during both of the probe trials (transfer test 1, main effect of quadrant, $F_{(3,117)}=13.30 ; p<$ 0.0001 ; transfer test 2 , main effect of quadrant, $F_{(3,117)}=18.28$; $p<0.0001)$. However, there were again no group differences in either test (transfer test 1, main effect of group and group-byquadrant interaction, both $F<1$; transfer test 2, main effect of group, $F<1$, group-by-quadrant interaction, $F_{(6,117)}=1.31 ; p>$ $0.20)$. An alternative way of analyzing the platform crossings data is to calculate an accuracy score based on the number of platform crossings in the four quadrants (accuracy score $=$ TRA $-[(\mathrm{OPP}$ + ADJL + ADJR)/3], where TRA, OPP, ADJL, and ADJR are the number of platform crossings in the training, opposite, adjacent left, and adjacent right quadrants, respectively). Again, this revealed no group differences in either of the transfer tests (transfer test $1, F<1$; transfer test $\left.2, F_{(2,39)}=1.65 ; p>0.20\right)$.

\section{Experiment 2: spatial working memory on the}

elevated T-maze

SWM was then assessed using a hippocampus-dependent, discrete-trial, rewarded alternation task (spatial non-matchingto-place) on an elevated T-maze. Wild-type mice showed excellent alternation, but both $N R 2 A^{-1-}$ and $N R 2 A^{\Delta C / \Delta C}$ mice displayed a reduced level of SWM performance (main effect of group, $F_{(2,37)}=8.62 ; p<0.001$; Student-Newman-Keuls at $p<$ 0.01 for wild-type vs both $N R 2 A^{-1-}$ and $N R 2 A^{\Delta C / \Delta C}$ mice, which themselves did not differ) (Fig. 2). ANOVA also revealed a main effect of block $\left(F_{(4,148)}=3.64 ; p<0.01\right)$, but there was no groupby-block interaction $\left(F_{(8,148)}=1.38 ; p>0.20\right)$.

\section{Experiment 3: assessment of spatial memory on the radial maze}

Spatial reference memory acquisition

The dissociation between SRM and SWM was confirmed in a simultaneous test using a hippocampus-dependent radial maze task (Olton et al., 1979; Schmitt et al., 2003). Mice were first trained solely on the SRM component of the task. Doors stopped the mice from reentering an arm that they had already visited on that trial, thus preventing SWM errors. SRM errors were scored

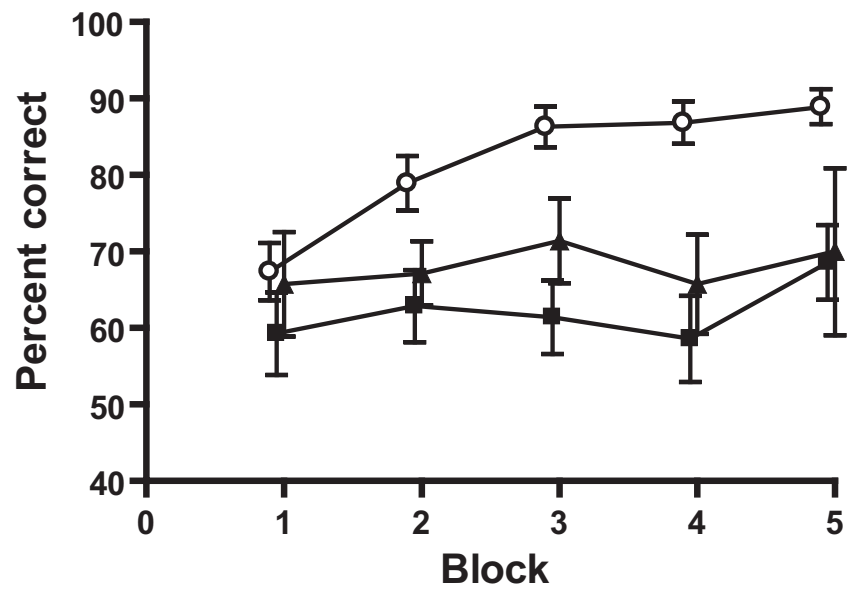

Figure 2. Normal NR2A expression is required for spatial working memory performance. Rewarded alternation on the elevated T-maze: mean percentages of correct responses \pm SEM per block of 10 trials for wild-type $(O), N R 2 A^{-/-}(\boldsymbol{\square})$, and $N R 2 A^{\Delta C / \Delta C}$ mice $(\boldsymbol{\Delta})$ are shown.

when a mouse entered an arm that was never baited. All mice learned the SRM task at the same rate (main effect of block, $F_{(14,420)}=112.01 ; p<0.0001 ;$ main effect of genotype, $F_{(2,30)}=$ 2.44; $p>0.10$; and genotype-by-block interaction, $F_{(28,420)}=$ $1.26 ; p>0.10)$ (Fig. $3 A$ ).

Simultaneous assessment of spatial working and reference memory The SWM component was then introduced. All doors were open for every choice, so it was now possible to reenter previously visited (and now unrewarded) arms. SWM errors were scored if a mouse revisited an initially baited arm within a trial. SRM errors were scored as before. Both groups of mutant mice were less able to keep track of which arms they had already visited and thus made more SWM errors than wild-type mice (main effect of genotype, $F_{(2,30)}=5.10 ; p<0.05$; Student-Newman-Keuls $p<$ 0.05 for wild-type vs both $N R 2 A^{-1-}$ and $N R 2 A^{\Delta C / \Delta C}$ mice) (Fig. $3 B$ ), although both mutants performed at a level above what would be expected by chance (a mouse performing at chance would be expected to make 1.33 errors in its first three choices). At the same time, $N R 2 A^{-1-}$ and $N R 2 A^{\Delta C / \Delta C}$ mice were still indistinguishable from controls in terms of being able to remember which arms were never baited (SRM errors; main effect of geno- 
A

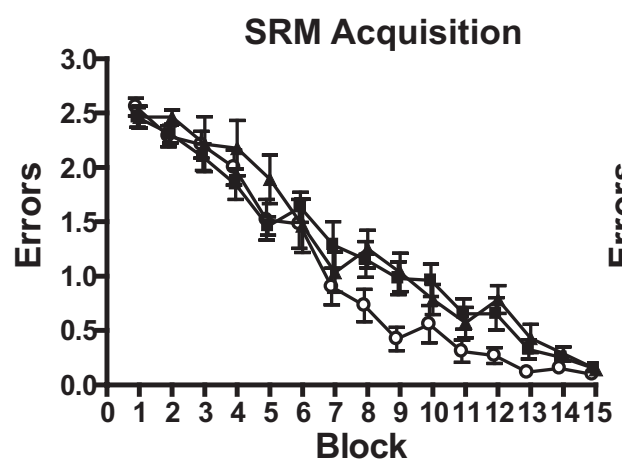

B

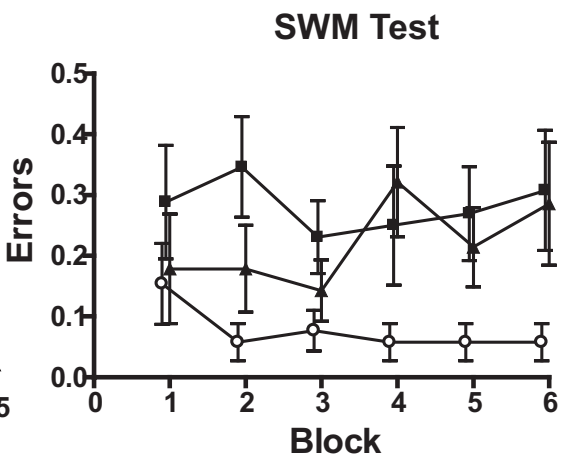

C

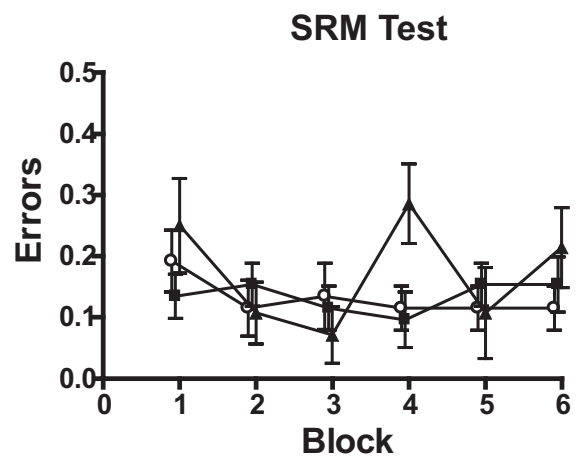

Figure 3. Within-task demonstration of impaired spatial working memory and spared spatial reference memory performance in NR2A-deficient mice on the radial maze. $\boldsymbol{A}$, Acquisition phase: mean reference memory errors per trial \pm SEM for wild-type $(\bigcirc), N R 2 A^{-/-}(\boldsymbol{\square})$, and NR2A $A^{\Delta C / \Delta C}$ mice $(\mathbf{\Delta})$ during 15 blocks (4 trials per block) of training on a three-of-six SRM radial maze task. $B$, Test phase: working memory errors per trial \pm SEM during six blocks of testing on a three-of-six SRM and SWM radial maze task. $C$, Test phase: reference memory errors per trial \pm SEM during six blocks of testing on a three-of-six SRM and SWM radial maze task.

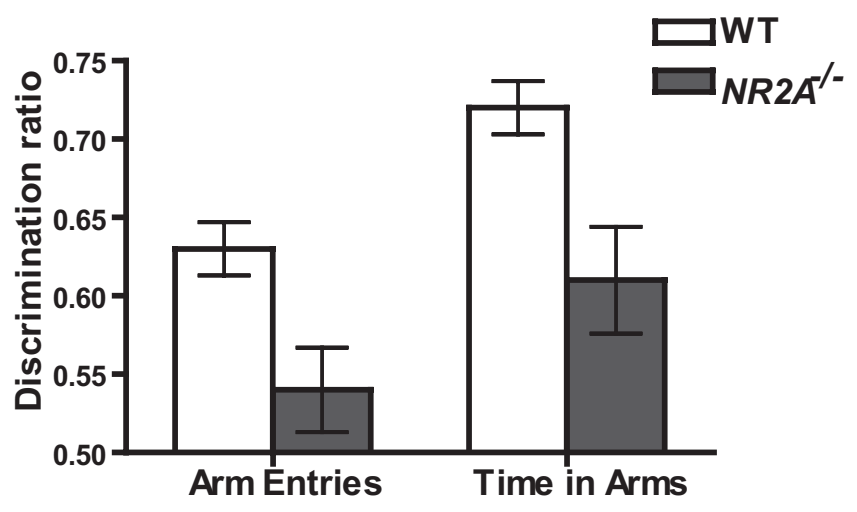

Figure 4. NR2A knock-out mice display a reduced spatial novelty preference. A discrimination ratio [novel/(novel + other)] was calculated for both the number of arm entries (left) and the time spent in the arms (right) for both wild-type (WT; white bar) and NR2A ${ }^{-1-}$ mice (gray bar) (chance performance, 0.50 ).

type, $F<1$; genotype-by-block interaction, $F_{(10,150)}=1.82 ; p>$ 0.05) (Fig. 3C). The intact SRM performance shows that disruption of NR2A-mediated signaling induces a specific SWM impairment rather than a non-mnemonic impairment of general maze behavior.

Experiment 4: spontaneous spatial novelty preference test During the exposure phase, wild-type and $N R 2 A^{-/-}$mice made a similar number of total arm entries, and the number of arm entries into the start and other arms did not differ (both $F<1$ ). Also, the amount of time spent exploring the start and other arm did not differ between the groups (effect of group and group-byarm interaction, $F<1$ ). During the test phase, the wild-type mice showed a strong preference for the novel (previously unvisited) arm (Fig. 4). This preference was reduced in the NR2 $A^{-1-}$ mice, although they still showed a small preference for the novel arm over the other arm. Statistical analysis of the discrimination ratios [novel arm/(novel + other arm)] for both the time spent in arms and the number of arm entries confirmed that the wild-type mice had a significantly stronger preference for the novel arm than the $N R 2 A^{-1-}$ mice. The wild-type mice made a higher proportion of novel arm entries $\left(F_{(1,44)}=10.06 ; p<0.005\right)$ and spent a significantly greater proportion of time in the novel arm $\left(F_{(1,44)}=\right.$ 11.03; $p<0.005)$. One-sample $t$ tests showed that the wild-type mice had a preference for the novel arm that was significantly above chance (discrimination ratio $=0.50$ ), both for arm entries and time spent in arms $\left(t_{(28)}>7.8 ; p<0.001\right)$. The discrimination ratio for the $N R 2 A^{-1-}$ mice was also significantly above chance in terms of the time spent in the arms $\left(t_{(18)}=3.39 ; p<\right.$ $0.005)$, although not for number of arm entries $\left(t_{(18)}=1.41 ; p>\right.$ $0.10)$. During the test phase, both groups of mice made a similar total number of arm entries into other and novel arms $(F<1)$ and spent a similar total amount of time in these arms $\left(F_{(1,44)}=\right.$ 2.77; $p>0.10)$. There were no significant effects of gender or interactions involving gender (all $p>0.20)$.

\section{Experiment 5: conditional learning on the T-maze \\ Contiguous task}

Separate groups of experimentally naive wild-type and NR2 $A^{-/-}$ mice were assessed using a T-maze task in which floor inserts provided a conditional cue indicating in which goal arm a milk reward was to be found (Murray and Ridley, 1999; Schmitt et al., 2004). Both wild-type and $N R 2 A^{-1-}$ mice ( $n=10$ per group) were able to acquire the task at a similar rate if the floor inserts extended throughout the entire maze, including the start arm and both goal arms (the hippocampus-independent version of the task; main effect of block, $F_{(13,234)}=23.26 ; p<0.0001$; main effect of genotype and genotype-by-block interaction, both $F<$ 1) (Fig. 5A).

\section{Discontiguous task}

In contrast, whereas wild-type mice $(n=10)$ could also acquire the hippocampus-dependent version of the task in which the floor inserts were only present in the start arm of the maze, $N R 2 A^{-/-}$mice $(n=10)$ were dramatically impaired and failed to acquire this task (main effect of group, $F<1$; main effect of block, $F_{(23,414)}=11.52 ; p<0.0001$; genotype-by-block interaction, $F_{(23,414)}=4.50 ; p<0.0001$ ) (Fig. $5 B$ ). Analysis of simple main effects showed that although the $N R 2 A^{-/-}$mice actually performed significantly better than the wild-type mice on block 8 of training $\left(F_{(1,103)}=4.03 ; p<0.05\right)$, they failed to acquire the task and were significantly impaired on blocks $18-21\left(F_{(1,103)}>4.57\right.$; $p<0.05)$ and blocks 23 and $24\left(F_{(1,103)}>6.45 ; p<0.05\right)$.

\section{Discussion}

NR2A mutant mice displayed perfectly normal SRM acquisition. This is surprising in view of (1) the widely held belief that NMDAR-dependent LTP in the adult hippocampus underlies 
spatial learning on tasks like the fixedlocation, hidden-platform water maze task; (2) the proposed role of the NR2A subunit in hippocampal LTP induction in adult animals (Liu et al., 2004); and (3) the original report of impaired SRM abilities in $N R 2 A^{-1-}$ mice (Sakimura et al., 1995). In the present study, SRM abilities were unaffected on two procedurally very different, hippocampus-dependent tasks, and in two different NR2A mutant lines $\left(N R 2 A^{-1-}\right.$ and $N R 2 A^{\Delta C / \Delta C}$ mice). However, both NR2A mutants exhibited impaired hippocampus-dependent SWM on two different appetitive maze tasks. In addition, $N R 2 A^{-1-}$ mice were impaired on a hippocampus-dependent, conditional T-maze task in which animals had to remember the floor insert indicating which goal arm contained reward (Schmitt et al., 2004). NR2 $A^{-1-}$ mice also displayed less spatial novelty preference than controls in a spontaneous exploration Y-maze task.

It is not immediately obvious why the outcome of the present water maze study is different from that reported by Sakimura et al. (1995). The most likely explanation relates to differences in the genetic background of the mice in the two studies. It is well established that differences in genetic background of genetically modified mice can affect the outcome of behavioral studies (Crawley, 1996; Gerlai, 1996; Wolfer and Lipp, 2000). NR2A ${ }^{-1-}$ mice were initially produced by homologous recombination in ES cells from a C57BL/6 $\times$ CBA F1 hybrid, using a targeting vector with genomic DNA from a C57BL/6 mouse (Sakimura et al., 1995). These mice therefore had a degree of CBA character. They were then subsequently back-crossed repeatedly with C57BL/6 mice to yield $N R 2 A^{-/-}$and wild-type mice on a more pure C57BL/6 genetic background (Kiyama et al., 1998). By the F13 generation, the behavioral performance in the wild-type mice closely resembled that of C57BL/6 mice (after 13 backcrosses, $90-95 \%$ of the genes are homozygous and of C57BL/6 origin), in contrast to wild-type mice from the F2 generation, which more resembled CBA mice. It is well established that C57BL/6 mice perform better in the water maze than CBA mice (Schimanski and Nguyen, 2004), and therefore the original water maze deficit may have reflected a higher degree of CBA character in the background genes selected specifically with the knock-out mice. In contrast, by the time of the present study, the mice were on a more pure C57BL/6 background, and hence there were no differences between wild-type and mutant mice in the water maze.

Both $N R 2 A^{-1-}$ and $N R 2 A^{\Delta C / \Delta C}$ mutants did, however, display impaired SWM performance. The SWM deficit in $N R 2 A^{-/-}$ mice is consistent with previous pharmacological studies. AP5 produces SWM impairments in a number of experimental paradigms, suggesting a crucial and obligatory role for NMDARs in a rapid, flexible hippocampal memory system (Tonkiss and Rawlins, 1991; Steele and Morris, 1999; Lee and Kesner, 2002; Day et al., 2003; Bast et al., 2005). More recently, we have shown that acute infusion of D-AP5 directly into dorsal hippocampus impairs SWM performance on the T-maze rewarded alternation task (McHugh et al., 2008). These pharmacological results support the hypothesis that the SWM impairments in the NR2A mutants are a direct consequence of impaired NMDAR function
B

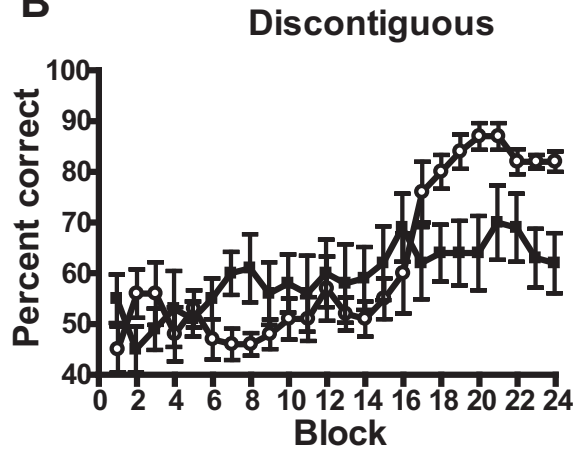


tants may reflect the less robust disruption of hippocampal LTP in these animals.

It should be noted, however, that we cannot definitively rule out the possibility that deletion of the NR2A subunit in brain areas outside the hippocampus could also contribute to the observed SWM impairment. However, there remains a convincing argument for a hippocampal phenotype. First, it is worth considering whether a hippocampus-specific manipulation can give rise to this kind of behavioral phenotype. We recently showed that genetically modified mice in which the NR1 NMDAR subunit has been deleted specifically from, and exclusively within, the dentate gyrus, also show normal SRM but impaired SWM (Niewoehner et al., 2007). Second, it is worth considering a possible frontal contribution to the phenotype (for discussion, see Schmitt et al., 2003). Rodents with mPFC lesions are in fact perfectly capable of learning the spatial non-matching-to-place rule (Touzani et al., 2007), and can perform perfectly well on these SWM tasks even at longer delays (Gisquet-Verrier and Delatour, 2006). Indeed, these more recent studies have suggested that the $\mathrm{mPFC}$ "is not directly involved in the short-term maintenance of specific information but is implicated when changes, such as the sudden introduction of a delay or exposure to unexpected interfering events, alter the initial situation." (Gisquet-Verrier and Delatour, 2006) (see also Touzani et al., 2007). This is in obvious contrast to the robust and lasting impairments that have been observed after lesions of the septohippocampal formation (Deacon et al., 2002) or after either GluR-A (Reisel et al., 2002) or NR2A deletion (this study).

To conclude, these results further strengthen the link between rapid, flexible spatial memory processing and NMDARdependent hippocampal synaptic plasticity. Furthermore, they provide further evidence for the existence of distinct aspects of spatial information processing. First, there is a NR2Aindependent, incremental spatial memory mechanism through which the association between a particular spatial response and an outcome (e.g., an escape platform or food reward) may be gradually strengthened, and which presumably underlies performance on tasks such as the fixed-location, hidden-platform water maze task. Second, there is a separate information-processing mechanism through which the spatial responses of animals can be controlled rapidly and flexibly on the basis of information retrieved from recent memory. That information can be either spatial in nature (in terms of the prior movements of the mouse, e.g., during T-maze rewarded alternation, win-shift behavior on the radial maze, or the exposure phase of the spatial novelty preference test), or can be provided by nonspatial stimuli (e.g., floor inserts in the conditional T-maze task). It is parsimonious to suggest that the performance of wild-type mice on T-maze rewarded alternation, win-shift behavior on the radial maze, and the spatial novelty preference test all rely on the ability to judge the relative familiarity of the maze arms and select the least familiar option. This ability may simply reflect a short-term habituation process, resulting from the rapid formation of a nonassociative memory trace (Wagner, 1981; Sanderson et al., 2007). Acquisition of the discontiguous conditional discrimination task also requires the animal to be able to judge the relative familiarity of the different conditional cues and thus associate the most recently experienced floor insert with a particular spatial response being rewarded. This rapid form of information processing can be initiated through NR2A-containing NMDAR activation, involves the GluR-A-dependent modification of postsynaptic AMPA receptors (Malinow and Malenka, 2002), and the signal- ing pathway is dependent, at least in part, on the C-terminal intracellular domain of the NR2A subunit.

\section{References}

Bannerman DM, Good MA, Butcher SP, Ramsay M, Morris RG (1995) Distinct components of spatial learning revealed by prior training and NMDA receptor blockade. Nature 378:182-186.

Bannerman DM, Rawlins JN, Good MA (2006) The drugs don't work-or do they? Pharmacological and transgenic studies of the contribution of NMDA and GluR-A-containing AMPA receptors to hippocampaldependent memory. Psychopharmacology (Berl) 188:552-566.

Bast T, da Silva BM, Morris RG (2005) Distinct contributions of hippocampal NMDA and AMPA receptors to encoding and retrieval of one-trial place memory. J Neurosci 25:5845-5856.

Berberich S, Punnakkal P, Jensen V, Pawlak V, Seeburg PH, Hvalby O, Kohr G (2005) Lack of NMDA receptor subtype selectivity for hippocampal long-term potentiation. J Neurosci 25:6907-6910.

Berberich S, Jensen V, Hvalby O, Seeburg PH, Kohr G (2007) The role of NMDAR subtypes and charge transfer during hippocampal LTP induction. Neuropharmacology 52:77-86.

Crawley JN (1996) Unusual behavioral phenotypes of inbred mouse strains. Trends Neurosci 19:181-182; discussion 188-189.

Day M, Langston R, Morris RG (2003) Glutamate-receptor-mediated encoding and retrieval of paired-associate learning. Nature 424:205-209.

Deacon RM, Bannerman DM, Kirby BP, Croucher A, Rawlins JN (2002) Effects of cytotoxic hippocampal lesions in mice on a cognitive test battery. Behav Brain Res 133:57-68.

Delatour B, Gisquet-Verrier P (1999) Lesions of the prelimbic-infralimbic cortices in rats do not disrupt response selection processes but induce delay-dependent deficits: evidence for a role in working memory? Behav Neurosci 113:941-955.

Gerlai R (1996) Gene-targeting studies of mammalian behavior: is it the mutation or the background genotype? Trends Neurosci 19:177-181.

Gisquet-Verrier P, Delatour B (2006) The role of the rat prelimbic/infralimbic cortex in working memory: not involved in the short-term maintenance but in monitoring and processing functions. Neuroscience 141:585-596.

Hoffman DA, Sprengel R, Sakmann B (2002) Molecular dissection of hippocampal theta-burst pairing potentiation. Proc Natl Acad Sci USA 99:7740-7745

Jensen V, Kaiser KM, Borchardt T, Adelmann G, Rozov A, Burnashev N, Brix C, Frotscher M, Andersen P, Hvalby O, Sakmann B, Seeburg PH, Sprengel $\mathrm{R}$ (2003) A juvenile form of postsynaptic hippocampal long-term potentiation in mice deficient for the AMPA receptor subunit GluR-A. J Physiol (Lond) 553:843-856.

Kiyama Y, Manabe T, Sakimura K, Kawakami F, Mori H, Mishina M (1998) Increased thresholds for long-term potentiation and contextual learning in mice lacking the NMDA-type glutamate receptor $\varepsilon 1$ subunit. J Neurosci 18:6704-6712.

Kohr G, Jensen V, Koester HJ, Mihaljevic AL, Utvik JK, Kvello A, Ottersen OP, Seeburg PH, Sprengel R, Hvalby O (2003) Intracellular domains of NMDA receptor subtypes are determinants for long-term potentiation induction. J Neurosci 23:10791-10799.

Lee I, Kesner RP (2002) Differential contribution of NMDA receptors in hippocampal subregions to spatial working memory. Nat Neurosci 5:162-168.

Liu L, Wong TP, Pozza MF, Lingenhoehl K, Wang Y, Sheng M, Auberson YP, Wang YT (2004) Role of NMDA receptor subtypes in governing the direction of hippocampal synaptic plasticity. Science 304:1021-1024.

Malinow R, Malenka RC (2002) AMPA receptor trafficking and synaptic plasticity. Annu Rev Neurosci 25:103-126.

Martin SJ, Grimwood PD, Morris RG (2000) Synaptic plasticity and memory: an evaluation of the hypothesis. Annu Rev Neurosci 23:649-711.

McHugh SB, Niewoehner B, Rawlins JN, Bannerman DM (2008) Dorsal hippocampal $N$-methyl-D-aspartate receptors underlie spatial working memory performance during non-matching to place testing on the T-maze. Behav Brain Res 186:41-47.

Morishita W, Lu W, Smith GB, Nicoll RA, Bear MF, Malenka RC (2007) Activation of NR2B-containing NMDA receptors is not required for NMDA receptor-dependent long-term depression. Neuropharmacology $52: 71-76$ 
Morris RG, Garrud P, Rawlins JN, O’Keefe J (1982) Place navigation impaired in rats with hippocampal lesions. Nature 297:681-683.

Morris RG, Anderson E, Lynch GS, Baudry M (1986) Selective impairment of learning and blockade of long-term potentiation by an N-methyl-Daspartate receptor antagonist, AP5. Nature 319:774-776.

Murray TK, Ridley RM (1999) The effect of excitotoxic hippocampal lesions on simple and conditional discrimination learning in the rat. Behav Brain Res 99:103-113.

Nagy A, Rossant J, Nagy R, Abramow-Newerly W, Roder JC (1993) Derivation of completely cell culture-derived mice from early-passage embryonic stem cells. Proc Natl Acad Sci USA 90:8424-8428.

Nakazawa K, Sun LD, Quirk MC, Rondi-Reig L, Wilson MA, Tonegawa S (2003) Hippocampal CA3 NMDA receptors are crucial for memory acquisition of one-time experience. Neuron 38:305-315.

Niewoehner B, Single FN, Hvalby O, Jensen V, Borgloh SM, Seeburg PH, Rawlins JN, Sprengel R, Bannerman DM (2007) Impaired spatial working memory but spared spatial reference memory following functional loss of NMDA receptors in the dentate gyrus. Eur J Neurosci 25:837-846.

Olton DS, Becker JT, Handelmann GE (1979) Hippocampus, space, and memory. Behav Brain Sci 2:313-365.

Reisel D, Bannerman DM, Schmitt WB, Deacon RM, Flint J, Borchardt T, Seeburg PH, Rawlins JN (2002) Spatial memory dissociations in mice lacking GluR1. Nat Neurosci 5:868-873.

Sakimura K, Kutsuwada T, Ito I, Manabe T, Takayama C, Kushiya E, Yagi T, Aizawa S, Inoue Y, Sugiyama H, Mishina M (1995) Reduced hippocampal LTP and spatial learning in mice lacking NMDA receptor epsilon 1 subunit. Nature 373:151-155.

Sanderson DJ, Gray A, Simon A, Taylor AM, Deacon RM, Seeburg PH, Sprengel R, Good MA, Rawlins JN, Bannerman DM (2007) Deletion of glutamate receptor-A (GluR-A) AMPA receptor subunits impairs one-trial spatial memory. Behav Neurosci 121:559-569.

Saucier D, Cain DP (1995) Spatial learning without NMDA receptordependent long-term potentiation. Nature 378:186-189.

Schimanski LA, Nguyen PV (2004) Multidisciplinary approaches for investigating the mechanisms of hippocampus-dependent memory: a focus on inbred mouse strains. Neurosci Biobehav Rev 28:463-483.

Schmitt WB, Deacon RM, Seeburg PH, Rawlins JN, Bannerman DM (2003) A within-subjects, within-task demonstration of intact spatial reference memory and impaired spatial working memory in glutamate receptor-Adeficient mice. J Neurosci 23:3953-3959.

Schmitt WB, Arianpour R, Deacon RM, Seeburg PH, Sprengel R, Rawlins JN,
Bannerman DM (2004) The role of hippocampal glutamate receptor-Adependent synaptic plasticity in conditional learning: the importance of spatiotemporal discontiguity. J Neurosci 24:7277-7282.

Schmitt WB, Sprengel R, Mack V, Draft RW, Seeburg PH, Deacon RM, Rawlins JN, Bannerman DM (2005) Restoration of spatial working memory by genetic rescue of GluR-A-deficient mice. Nat Neurosci 8:270-272.

Sprengel R, Suchanek B, Amico C, Brusa R, Burnashev N, Rozov A, Hvalby O, Jensen V, Paulsen O, Andersen P, Kim JJ, Thompson RF, Sun W, Webster LC, Grant SG, Eilers J, Konnerth A, Li J, McNamara JO, Seeburg PH (1998) Importance of the intracellular domain of NR2 subunits for NMDA receptor function in vivo. Cell 92:279-289.

Steele RJ, Morris RG (1999) Delay-dependent impairment of a matchingto-place task with chronic and intrahippocampal infusion of the NMDAantagonist D-AP5. Hippocampus 9:118-136.

Steigerwald F, Schulz TW, Schenker LT, Kennedy MB, Seeburg PH, Kohr G (2000) C-terminal truncation of NR2A subunits impairs synaptic but not extrasynaptic localization of NMDA receptors. J Neurosci 20:4573-4581.

Tonkiss J, Rawlins JN (1991) The competitive NMDA antagonist AP5, but not the non-competitive antagonist MK801, induces a delay-related impairment in spatial working memory in rats. Exp Brain Res 85:349-358.

Touzani K, Puthanveettil SV, Kandel ER (2007) Consolidation of learning strategies during spatial working memory task requires protein synthesis in the prefrontal cortex. Proc Natl Acad Sci USA 104:5632-5637.

Tsien JZ, Huerta PT, Tonegawa S (1996) The essential role of hippocampal CA1 NMDA receptor-dependent synaptic plasticity in spatial memory. Cell 87:1327-1338.

Wagner AR (1981) SOP: A model of automatic memory processing in animal behavior. In: Information processing in animals: memory mechanisms (Spear NE, Miller RR, eds), pp 5-47. Hillsdale, NJ: Erlbaum.

Wolfer DP, Lipp HP (2000) Dissecting the behaviour of transgenic mice: is it the mutation, the genetic background, or the environment? Exp Physiol 85:627-634.

Yagi T, Tokunaga T, Furuta Y, Nada S, Yoshida M, Tsukada T, Saga Y, Takeda N, Ikawa Y, Aizawa S (1993) A novel ES cell line, TT2, with high germline-differentiating potency. Anal Biochem 214:70-76.

Zamanillo D, Sprengel R, Hvalby O, Jensen V, Burnashev N, Rozov A, Kaiser KM, Koster HJ, Borchardt T, Worley P, Lubke J, Frotscher M, Kelly PH, Sommer B, Andersen P, Seeburg PH, Sakmann B (1999) Importance of AMPA receptors for hippocampal synaptic plasticity but not for spatial learning. Science 284:1805-1811. 